descriptions of arc-furnace techniques were given by Jones, Knapton and Savill, who also considered electron bombardmont heating as supplementary to arc-furnace techniques. Finally, a special molybdenum-wound cooling curve furnace was described by W. Oldfield (British Cast Iron Research Association), in which the element completely surrounds the specimen container.

\section{Physical Properties and Equilibria at High Temperatures}

The first two papers were concerned with crystal structure. A. J. Martin and A. Moore (Atomic Weapons Research Establishment, Aldermaston) discussed the structure of beryllium at temperatures between $-185^{\circ} \mathrm{C}$. and $1,290^{\circ} \mathrm{C}$. No evidence was found to support other workers' claims of allotropy in the range $400-800^{\circ} \mathrm{C}$. They showed, however, that the lattice is hexagonal up to about $1,250^{\circ} \mathrm{C}$., above which the structure is body-centred cubic, and the authors discussed the possibilities of retaining this structure form at temperatures below $1,250^{\circ} \mathrm{C}$.

The Metallurgy Department, Royal Aircraft Establishment, Farmborough, then presented a paper on the structures of graphites deposited from hydrocarbon gases at various temperatures and pressures. The effect of changes in deposition temperature on the density and X-ray diffraction pattern was shown. 'Flecks', not unlike deformation bands, are produced on the surface of these graphites when they are deformed.

The remaining papers of the session were concerned with high-temperature equilibria; C. W. Haworth (University of Oxford) described tungstenresistor furnaces in which specimens weighing $1-5 \mathrm{gm}$. can be annealed in vacuo or in argon up to $2,700^{\circ} \mathrm{C}$. and then quenched. The apparatus has been used in work on molybdenum base alloys. A. Hellawell (University of Oxford) directed attention to the facecentred cubic/body-centred cubic transition found in the metals of the first three transition series, and described apparatus which has been used in the thermal analysis of these phase transitions. The influence of various solute elements upon the transition in manganese and iron was shown to be related to the structures of the elements concerned.

The last paper of the session, by P. Gross, D. L. Levi and G. Wilson (Fulmer Research Institute), discussed methods for determining the thermodynamic activities of alloy constituents at high temperatures. Two methods for measuring vapour or reaction pressures have been used-an effusion method (restricted to systems in which the pressure of any constituent does not exceed about $0.1 \mathrm{~mm}$. mercury) applied to alloys containing iron and aluminium at $1,300^{\circ} \mathrm{C}$., and also a capillary vessel method where the reaction pressures are beyond the range of the effusion method.

\section{Mechanical Properties at High Temperatures}

In a paper on high-temperature mechanical working of molybdenum, E. W. Ward (Woolwich) discussed the factors affecting the breakdown of the are-cast structure. The microstructures produced by rolling and extruding at temperatures up to $1,800^{\circ} \mathrm{C}$. showed that true hot working had been achieved.

Two papers concerned with the measurement of mechanical properties followed. L. M. T. Hopkins (National Physical Laboratory) described determinations of the creep properties of ceramics and high melting-point metals in air and in vacuo, respectively. B. L. Mordike and L. M. Fitzgerald (University of Cambridge) are investigating the properties of the refractory metals tantalum, tungsten, niobium and molybdenum, and the carbides of tantalum, tungsten, niobium, titanium, zirconium, vanadium and boron up to their melting points, which lie in the range $2,500-3,500^{\circ}$ C. Apparatus to measure the tensile strength of metals, friction of carbides and hardness determinations of metals and carbides were described.

D. M. Gilbey (Farnborough) presented an extension of the simple theory of the thermal stresses in flat plates, so that variations with temperature and stress of the thermal and elastic properties of the material can be taken into account. The stresses calculated by this method for a manufactured graphite were compared with those obtained from the simple theory using constant 'effective values' of the 'constants'.

The session concluded with a paper by D. T. Livey (Harwell) on the high-temperature stability of oxides and sulphides. The behaviour of the stable refractory oxides in vacuo, oxidizing and reducing atmospheres was considered; the refractory sulphides are thermodynamically less stable, in general, than the oxides, although the sulphides of cerium and thorium have been used for reactive metals. Kinetic factors, rathet than thermodynamic stability, control the degree of reaction between metals and oxides or sulphides, ar least for the more reactive metals.

During the symposium, an exhibition of apparatus, refractories, etc., was held at the University Department of Metallurgy. Exhibits were lent by a number of industrial firms, research establishments, and university departments.

\section{J. W. MARTIN}

\title{
INVASIVENESS AND SURFACE PROPERTIES OF CANCER CELLS
}

$\mathrm{A}^{\mathrm{N}}$ informal symposium on the surface properties of cells and their possible bearing on the invasive movements of cancer cells was held at the Chester Beatty Research Institute on July 4. The chair at the morning session was taken by Prof. A. Haddow and in later sessions by Dr. B. Sylvén (Stockholm) and Prof. G. Klein (Stockholm).

Prof. Haddow pointed out in his introductory remarks that the bearing of the surface properties of cancer cells on their invasiveness has received little attention, apart from the microhistological studies of Dr. Cornan and his collaborators in the United States.
But interest in the surface properties of cancer cells has developed during the past few years; stimulated largely by Dr. M. Abercrombie's studies of cell movements in tissue culture. It had, therefore, been decided to bring together some of those specialists most directly concerned with this largely unexplored field.

Dr. M. Abercrombie (London) then described the conditions for the invasion of normal cell explants by tumour cells in culture. Whether or not invasion occurs appears to be determined largely by the effect that contact between interacting cells has on their 
locomotion. In the cell species so far studied, it is found that sarcoma cells invade explants of normal fibroblasts, whereas populations of normal fibroblasts do not invade each other. Sarcoma cells invade because they treat normal fibroblasts like any other substrate for their locomotion. They adhere to and are guided by oriented structure in any substrate, whether cellular or non-cellular.

To a normal fibroblast other fibroblasts are not simply equivalent to substrates; they are obstacles to locomotion. Contact with them results in an adhesion, immobilizing the small-scale membrane activity in its noighbourhood and stopping the cell from advancing in the direction of the adhesion. This is contact inhibition (Abercrombie and Heaysman, 1954; Abercrombie and Ambrose, 1958). Its nature is unknown, but it is possible to reduce it by changing the composition of the liquid phase of the culture (Curtis, unpublished). The behaviour of fibroblasts towards sarcoma cells appears to be different from the behaviour of sarcoma cells to fibroblasts. There is some inhibition of fibroblast locomotion by sarcoma cells which seems to be effected through a diffusible agent. A small number of experiments have shown that explants of sarcoma cells of different type invade each other.

Is it possible that the loss of contact inhibition and increased activity of the cell membrane is related to the uncontrolled growth of tumours? Prof. M. Swann (Edinburgh) described some interesting observations on the growth of soil amœebæ, which suggest that in this organism growth is affected by contacts. Mr. D. Harrison, working in Edinburgh, had studied the growth of Hartmanella in sterile culture. Growth in this case appears to be limited by mutual contact, which is reflected, after an early exponential phase, in the fact that the growth-curve of an amceba culture becomes linear over a considerable range, before it finally flattens out. A variety of experiments have shown that this is not due to environmental conditions, but solely to cell contacts. The linear phase can be abolished by treatment with antisera, when the growth-curve remains exponential for much longer. It seems possible that the contact effect is a direct mechanical inhibition of vacuole intake. Treatment with antiserum presumably prevents close contact and so abolishes the inhibition of growth by contact. Although experimentally difficult to carry out, a similar investigation using mammalian cells would be of great interest.

Various physico-chemical techniques are now being used for a direct study of the nature of the cell surface ; they were described by Dr. G. C. Easty (London). He first referred to earlier work on the erythrocyte membrane, which indicates that it is of a lipoprotein nature. A direct examination of the membrane is more difficult with mammalian cells, but it is known that tumour cells carry a net negative electrical surface charge which is almost twice that of the homologous normal cells (Ambrose, James and Lowick). Further information has been obtained by G. C. Easty, D. M. Easty and E. J. Ambrose, who have studied the effect of enzymes upon the adhesiveness of tumour cells to glass surfaces by a new centrifugation technique. The most effective enzymes for breaking contacts between ascites tumour cells and glass have proved to be lipase, phosphatases and elastase. These enzymes are thought to react with lipid, phosphate groups and protein, suggesting that the tumour cell surface is also composed of lipoprotein. 'The increased negative electrical charge could, therefore, be due to an excess of phosphate groups of phospholipid.

A more general biological approach to the changes in cell populations arising during transformation from normal to tumour tissue was then considered by Prof. and Mrs. G. Klein (Stockholm). They have obtained most interesting evidence for a progressive transformation in sublines derived by selective transplantation from a single tumour (MCIM sarcoma). The $M_{S S}$ sublines are solid tumours which do not readily produce ascites cells when transferred to the peritoneum, and only produce metastases very late in the growth of the tumour. The $M_{A S}$ sublines readily form ascites tumours and produce early metastases. These stepwise changes in biological characteristics can be correlated quite well with surface changes, the more anaplastic cell types $\left(M_{A S}\right)$ showing a higher electrical charge than the $M_{S S}$ types (Purdom, Klein and Ambrose).

Prof. E. Wolff (France) described a valuable technique using organ culture with mixed tissues and mixed species for the study of invasive movements. Real organ chimeras can be produced from associated duck and mouse testes in which testicular tubules may be formed from cells of the mixed species. In fragments of chick and mouse lung also, the mouse bronchial tubes grow and branch in pure chick connective tissue. Sometimes the two epithelia join and form a common canal. These results indicate that homologous tissues of the two species show more mutual affinities than heterologous tissues of the same species. Several sarcomas have been examined under the same conditions by Prof. Wolff. Fusion between embryo and tumour first occurs. All tumours then show a marked tendency to invade a number of organs, such as mesonephros, metanephros, gonad, skin, intestinal coat, lung, liver, etc. Carcinoma cells show a marked tendency to invade similar tissues to sarcomas, although they retain some capacity to proliferate as dense gatherings or secondary nodules.

Direct histological studies of growing tumours were described by Dr. B. Sylvén (Stockholm). With epithelial tissues in both normal regeneration and tumour growth, the connective tissue exhibits the following changes: (1) a general increase in water content; (2) an increased metachromatic component and (3) appearance of alkaline phosphatase in the ground substance. The extent of the changes gives a measure of the growth-rate and degree of malignancy of the tumour. With normal regeneration, the original connective tissue structure is reversibly restored with cessation of growth. The actual invasion of neighbouring tissues by tumour cells is seen to occur through channels and cavities already present in the normal structures; in addition, a considerable release of enzymes, particularly proteases, occurs. Such a transformation suggests a primary defect in the organization of the malignant cell membrane leading to increased permeability. Incidentally, malignant cells also show an increased permeability to glucose. Such a penetration of enzymes could remove surface adsorbed protein and account for the decreased adhesiveness and high negative charge of tumour cells.

Prof. K. Setälä (Helsinki) then described some experiments which may give a bearing on the actual mechanism of the cellular transformation which gives rise to the altered properties of tumour cells. He described how a number of surface-active agents of the 'Tween' detergent type can act as powerful promoters in carcinogenesis ; that is, they lead to a 
marked increase in tumour incidence when combined with a given carcinogen. Electron microscopy of the epidermal cells of the interfollicular areas of a mouse's back indicate that marked changes in cell contacts with intercellular gaps and bridges are produced by the promoting agents. Surface-active agents which do not act as promoters, on the other hand, lead to an actual hindrance of proliferation and increased regions of close contact between the cells.

Dr. E. H. Mercer (London) also described some of the valuable results he has obtained by high-resolution electron microscopy of cell contacts. Electron micrographs of cell membranes (Birbeck and Mercer) indicate that they consist of a layer structure about $60 \mathrm{~A}$. thick which could correspond to the lipid lying between protein layers, as proposed by Prof. J. F. Danielli. The membranes are generally separated by a distance of 150-200 A., suggesting the presence of a cementing material between the cells. Anaplastic tumours often show changes in their cell contacts as compared with normal tissues. They may show a convoluted surface with only small areas of contact; the contacts are more like those of normal cells during the early stages of tissue formation. The electron microscopy, therefore, supports the view that the surface properties of tumour cells are changed in comparison with the normal cells from which they are derived.
In conclusion, mention may be made of two other techniques which are being applied to the problem of cell movements and cell contacts. Dr. H. Harris (Oxford) described a simple but most effective method which he has applied to the study of groups of white blood cells. A long exposure is made with dark-field illumination. On subsequent development of the plate, the paths of the moving cells are recorded as streaks on the photographic emulsion. This technique is particularly useful for the study of a taxis affecting the over-all direction of cell migration.

Finally, Dr. R. J. Goldacre (London) described an approach based on the use of electronic models. In normal growth and maintenance the transfer of information from cell to cell evidently occurs. Direct contacts between the cell membranes appear to play a part in this, at least in the early stages of development. An electronic model consisting of units ('cells') which can stimulate and be stimulated by others can be designed. By connecting the units together in different groups, various complex patterns of interest in morphogenesis are generated in the system; for example, patterns with polarity, discrete differences between neighbouring units, etc. On the basis of such a picture, it would be expected that a small loss of cell - cell interaction, arising from surface changes, could readily lead to abnormal and uncontrolled growth in tumour tissues.

E. J. Ambrose

\section{PREDICTING ACADEMIC SUCCESS}

$\mathrm{T}$ HE purpose of a recent investigation by Sigvard Rubenowitz, of the Swedish Council for Personnel Administration, Gothenburg, was to determine the weights which have to be assigned to different tests and biographical data in order to predict success in academic studies*. The freshmen at the three universities in Gothenburg in 1954 were invited to take part in the investigation, the results of which would later be related to success at university as measured by examination results. Freshmen were chosen as subjects for the investigation in order to avoid bias in the results of the tests arising from different academic studies. In all, 440 , or 62 per cent, of the freshmen responded to the invitation.

After two years, information about examination results was collected and this was related to the data collected two years earlier.

The data collected and the tests which were given to the students were: (1) grades in the matriculation examination; (2) study habit assessments; (3) intelligence test marks; (4) technical test marks; (5) mathematical-technical test marks ; (6) organization test marks; (7) details of interests; (8) psychodiagnostic test assessment; and (9) attitude assessment.

Analysis of the results showed that of 43 female students who studied languages and 18 who were studying psychology the validation data in Table 1 were obtained.

It became clear that, for languages, more time is required for study than for other subjects. In addition, a significant correlation exists between intellectual and matriculation results on one hand and success in language studies on the other. The study habit also appears to be of great importance

* Occupational Psychology, 32, No. 3 (July 1958). in the study of languages. With psychology, general intelligence, together with those qualities which find expression in a good matriculation result, are not of such decisive importance as are certain mathematical technical aptitudes and some characterological factors that are measured by the Zulliger test.

Table 1

\begin{tabular}{|l|c|c|} 
& $\begin{array}{c}\text { Languages, } \\
\text { 43 students }\end{array}$ & $\begin{array}{c}\text { Psychology, } \\
\text { 18 students }\end{array}$ \\
\hline Grades in matriculation examination & 0.43 & 0.12 \\
Study habit inventory & 0.38 & 0.17 \\
Intelligence test & 0.40 & 0.28 \\
Technical test & 0.17 & 0.31 \\
Mathematical-technical test & 0.06 & 0.23 \\
Organization test & 0.04 & 0.28 \\
Psychodiagnostic test & 0.15 & 0.37 \\
Attitude assessment (the 'rigid' pole) & 0.21 & 0.25 \\
\hline
\end{tabular}

With certain male students the subject groups that formed the object of the validation were languages, psychology (philosophy), mathematics (statistics) and zoology (botany). The students of mathematics and statistics were, in general, superior to all others and above all in their intelligence and mathematicaltechnical ability. The male language students, like their female counterparts, made a significantly poor showing in their examination results.

The validation data in Table 2 were obtained from this inquiry.

Comparing these results with those for female students, the same trend is found except in the case of the matriculation result; this was of most value in prognosis for female students of languages, whereas for male students its value is highest for prognosis of psychological studies. 